\title{
Correction to: Admittance Controller with Spatial Modulation for Assisted Locomotion using a Smart Walker
}

\author{
Mario F. Jiménez ${ }^{1} \cdot$ Matias Monllor $^{2} \cdot$ Anselmo Frizera $^{1} \cdot$ Teodiano Bastos $^{1} \cdot$ Flavio Roberti $^{2} \cdot$ Ricardo Carelli $^{2}$ \\ Published online: 11 July 2018 \\ (C) Springer Nature B.V. 2018
}

Correction to: Journal of Intelligent \& Robotic Systems

https://doi.org/10.1007/s10846-018-0854-0

The original version of this article, unfortunately, contained errors.

Two occurrences of $H W E I$ found on the $6^{\text {th }}$ and $7^{\text {th }}$ pages should be presented as HREI.

In addition, the FAPES grant number in the Acknowledgment section is incorrect. This should read as "FAPES [grant number 80709036]."

Publisher's Note Springer Nature remains neutral with regard to jurisdictional claims in published maps and institutional affiliations.

The online version of the original article can be found at https://doi.org/10.1007/s10846-018-0854-0.

Mario F. Jiménez

mariof.jimenez@gmail.com; mario.hernandez@aluno.ufes.br

Matias Monllor

mmonllor@inaut.unsj.edu.ar

Anselmo Frizera

anselmo@ele.ufes.br

Teodiano Bastos

teodiano.bastos@ufes.br

Flavio Roberti

froberti@inaut.unsj.edu.ar

Ricardo Carelli

rcarelli@inaut.unsj.edu.ar

1 Postgraduate Program in Electrical Engineering, Federal University of Espírito Santo, 29075-910 Vitoria, Brazil

2 Institute of Automatics, National University of San Juan CONICET, San Juan 5400, Argentina 